\title{
El confesor del Emperador: la actividad política de fray García de Loaysa y Mendoza al servicio de Carlos V (1522-1530)
}

\author{
Guillermo Nieva Ocampo \\ CONICET / Universidad Nacional de Salta (Argentina)
}

RESUMEN: A lo largo del siglo XV los confesores de los monarcas castellanos de la dinastía Trastámara, en general dominicos, habian acrecentado su influencia política. De alli que la actividad de fray García de Loaysa en la corte de Carlos $V$ a partir del año 1522, como confesor regio y luego como Presidente del Consejo de la Inquisición y del Consejo de Indias, si bien no resulta extraña, no deja de suscitar admiración, justamente a raíz de la importancia de los cargos que ocupó en la corte, habiendo sido con anterioridad Maestro General de su propia orden religiosa. El presente artículo tiene como objeto abordar el estudio de este influyente y versátil personaje político, de su ascendiente carrera en la Orden de Predicadores y de su desempeño gubernamental en la corte de Carlos $V$, sobre todo en colaboración con la facción castellana de dicha corte, liderada por el secretario Francisco de los Cobos, mientras ejerció como confesor del emperador. Para ello nos valdremos de las crónicas de época, así como de una copiosa documentación reunida en los archivos españoles (Simancas y Nacional) y en los archivos de la Orden de Predicadores.

Palabras clave: Confesor real; siglo XVI; Carlos V; frailes dominicos.

The Confessor of Emperor: Political Activity of Friar Garcia de Loaysa y Mendoza Serving Charles V (1522-1530)

ABSTRACT: Throughout the 15th century the confessors of the Castilian monarchs of the Trastámara dynasty, mostly Dominican friars had increased their political influence. Therefore the friar Garcia de Loaysa's activity in the Court of Carlos $V$ from the year 1522, as Royal Confessor and then as President of the Council of the Inquisition and of the Council of the Indies, although it's not strange, nonetheless arouse admiration, precisely as 
a result of the importance of the charges in the Court having been previously Master General of his own religious order. The present paper aims to address the study of this versatile and influential political personage, of his rising career in the Order of Preachers and their government performance in the Court of Carlos V, mostly in collaboration with the Spanish faction of the Court, led by Secretary Francisco de los Cobos, while he served as confessor of the Emperor. For this we will use of the Chronicles of the time, as well as copious documentation gathered in Spanish archives (Simancas and National) and in the archives of the Order of Preachers.

KEY WORDS: Royal confessor; Sixteenth Century; Charles V; Dominican friars.

\section{INTRODUCCIÓN}

Desde el siglo XIV los eclesiásticos que gravitaban en la Corte de los reyes de Castilla, que servían en su Capilla, adquirieron funciones más especializadas, de allí que los cargos de capellanes reales y de confesores se distinguiesen uno de otro netamente, adquiriendo progresivamente estos últimos, en virtud del goce de la privanza, una gran influencia política ${ }^{1}$, situación que se verificó en modo recurrente a lo largo de la centuria siguiente. De hecho, figuras como las de Luis de Valladolid, confesor de Juan II, o de Lope Barrientos, confesor de Enrique IV, desarrollaron unas notables carreras eclesiásticas tras haber servido a los monarcas en el confesionario, oficio que conciliaron con el de embajadores o consejeros de Estado ${ }^{2}$. Se ha señalado, además, que, para desarrollar su oficio, un confesor real debía reunir una serie de características convencionales: castidad y vida honesta, preparación intelectual y discreción ${ }^{3}$.

Los confesores de los Reyes Católicos se ajustaron también a ese perfil, concertando la administración del sacramento con la función de consejero, siendo el desempeño de ese oficio un momento en la carrera eclesiástica de

1 Nogales Rincón considera que «las funciones de confesor real debieron de recaer inicialmente en el capellán mayor, posiblemente sin descartar la presencia de otros prelados en la Corte que ejercerían tales funciones de una forma informal. El confesor del rey adquirió pronto una especificidad propia respecto de la Capilla Real hasta separarse de la misma». NOGALES RINCÓN, 2009: 195.

2 En palabras de José Manuel Nieto Soria: «el acceso al cargo de confesor real supone el comienzo de una intensa carrera política y eclesiástica que lleva al confesor a asumir finalmente las máximas responsabilidades en el medio cortesano y al frente de la jerarquía eclesiástica castellana». NIETO SORIA, 1995: 140.

3 Sobre ello, así como sobre las funciones religiosas y de consejo que desempeñaron los confesores de los reyes de Castilla durante la Baja Edad Media. NOGALES RINCÓN, 2008: 55-80. 
quien lo ostentaba ${ }^{4}$. Por otro lado, en el caso de Isabel y Fernando, sus confesores, en general franciscanos o dominicos (salvo el caso del jerónimo Hernando de Talavera), procedían de la rama reformada de su propia orden, asunto para nada menor, si se considera que justamente el movimiento reformista y las mismas congregaciones de la reforma gozaban del patrocinio de la pareja real y estaban sumamente vinculadas a las estructuras de gobierno de la Monarquía ${ }^{5}$.

Sin embargo, con Carlos V se observan ciertos cambios en orden al acrecentamiento del prestigio del oficio de confesor, situación que se consolidó durante los reinados de sus sucesores a tal punto, que morir en el ejercicio de dicho cargo, sin que éste fuese considerado el trampolín para alcanzar otras dignidades, era señal de éxito ${ }^{6}$.

Justamente, el presente artículo tiene como objetivo el análisis de la trayectoria de un confesor del emperador, García de Loaysa y Mendoza, quien ejerció dicho oficio entre los años 1523 y 1530. Consideramos que con Loaysa se verificó una definición de las competencias del confesor regio, consecuencia de varios factores, entre ellos, el recambio político que se produjo en la Corte tras la Guerra de las Comunidades y las reformas que dieron origen en la década de 1520 al sistema polisinodial de gobierno de la Monarquía hispana.

\section{EL EMPERADOR, SU CORTE Y SU CONFESOR}

En 1520 Carlos V había tomado la decisión de renovar la tradición de sus abuelos nombrando un confesor-consejero, religioso proveniente de la rama reformada de una orden mendicante. En tal caso, y por mediación de Francisco de los Ángeles Quiñones ${ }^{7}$ y de Adriano de Utrecht, escogió a Jean Glapion, quien hasta entonces había ejercido como provincial de los franciscanos observantes de Francia ${ }^{8}$. Se ha creído ver en la promoción de Glapion, tras la renuncia del anterior confesor Jean Brisselot, la sombra de Guillermo de Croy, interesado en un acercamiento con el rey de Francia. No obstante, el nuevo confesor gozaba también del favor de la tía del emperador, Margarita de Austria, con quien había mantenido anteriormente una estrecha relación epistolar y de intercambio de favores espirituales. Al igual que la princesa,

4 NIETO SORIA, 1995: 131-132, 142-147.

5 NIEVA OCAMPO, 2012: 513-561.

6 POUTRIN, 2005: 67-81; PIZARRO LLORENTE, 1994: 149-188; CARLOS MORALES, 1998: 131-157; LÓPEZ ARANDIA, 2010: 249-278.

7 MEESTER, 2001: 197-213.

8 FERNÁNDEZ CONTI, 2000: 177-178. 
quien durante su regencia se había mostrado contraria a un acercamiento con Francia, Jean Gaplión había promovido en su Orden la autonomía de la custodia franciscana de Flandes en 1518, hasta entonces dependiente de la provincia parisina, que terminó en 1523 por convertirse en provincia de San Jerónimo.

Desde su cargo de confesor del emperador, Glapion colaboró en la represión del protestantismo y también en la creación de nuevos obispados en el círculo imperial borgoñón. De hecho, su poder en materia religiosa, en especial la referida a nombramientos, parece que fue muy amplia. Así lo revela una carta de Martín de Salinas, representante del infante Fernando en la Corte de Carlos V, aconsejando a su patrón, el 6 de julio de 1522, que «escriba al dicho confesor para que quiera tener la mano y proveer de su parte a dos capellanes que Su Alteza tiene consigo de nuestra patria [...] Y con estas letras el favor de vuestra merced para el confesor no dudo que cada uno de ellos, desde ahora, se pueden entitular» ${ }^{9}$.

Glapion se mostró partidario durante la Dieta de Worms de una reconciliación del emperador con el duque Federico de Sajonia, quien defendía a Lutero, con cuyas ideas simpatizaba ${ }^{10}$. Y es que el confesor estaba también convencido de la necesidad de una reforma de la Iglesia, si bien no está claro que fuese partidario de un cisma. Fraile de la observancia, se identificaba particularmente con el pensamiento de Erasmo y mantenía una relación cordial con numerosos franciscanos de Castilla, epígonos del cardenal Cisneros ${ }^{11}$. Del mismo modo, se manifestó partidario de una concordia con el rey de Francia, contando, en este caso, con el apoyo del gran chambelán Guillermo de Croy ${ }^{12}$, postura que el «partido flamenco» sostendría en la Corte de Carlos V hasta el saqueo de Roma de $1527^{13}$.

Cuando la corte llegó a España, en el verano de 1522, se incluyó al confesor real entre los miembros del flamante Consejo de Estado, creación promovida por el canciller Mercurino Arborio de Gattinara. Sin embargo, poco tiempo después, el 14 de septiembre, Jean Glapion, quien había llegado a conocer profundamente al joven emperador, moría inopinadamente en el monasterio de Santa Clara de Valladolid ${ }^{14}$.

9 RODRÍGUEZ VILLA, 1903: 52.

10 BRANDI, 1949: 109-110.

11 LIPPENS, 1951: 3-70; MARTÍNEZ MILLÁN, 2004: 97-126.

12 FAGEL, 1999: 29-63.

13 MARTÍNEZ MILLÁN, RIVERO RODRÍGUEZ, 2001: 131-150.

14 El embajador veneciano Gasparo Contarini dejó una información valiosa relativa a esta situación. El diplomático confesaba que si bien Carlos $\mathrm{V}$ era un príncipe comedido y para nada arrogante, «ben ha una parte non laudabile molto, dico d'inclinazione naturale; che, per quanto mi disse il suo confessore, col quale avevo qualche familiarità, dico il frate di san Francesco [Glapion], che morì in Vagliadolid, è naturalmente Cesare memore delle ingiurie 
La muerte de Glapion y unos días después la del obispo Mota, conllevó la extinción del primer grupo de consejeros «flamencos», que habían acompañado a Carlos $\mathrm{V}$ en los cinco primeros años de su gobierno, puesto que ya habían fallecido Jean Sauvage en 1518 y el mismo señor de Chièvres en $1521^{15}$. Por lo tanto, se produjo el relevo obligado de los personajes del entorno cortesano más próximo del monarca. A partir de entonces creció la influencia del canciller Gattinara - ayudado por el secretario Jean Lallemand- quien dirigía los asuntos imperiales, y también de Francisco de los Cobos, quien se ocupaba de los asuntos castellanos relacionados con la Cámara, las Indias y Hacienda. De hecho, hacia 1523, tal como ha señalado Martínez Millán:

Una vez fijadas las condiciones de servicio de las casas reales y atendidas buena parte de las demandas castellanas, se desató un soterrado e intenso antagonismo por el dominio de los principales cargos cortesanos y por ejercer mayor influjo en la persona del monarca, en el que paulatinamente se fueron imponiendo los miembros del antiguo «partido fernandino» encabezado por el secretario Francisco de los Cobos y por el cardenal Juan Tavera ${ }^{16}$.

Por su parte, García de Loaysa era desde el 1 de marzo de 1523 primer predicador en la capilla de la Casa castellana de Carlos V y desde el 23 de agosto de ese mismo año ejercía el cargo de confesor imperial ${ }^{17}$. Desde la muerte de Glapion el monarca había preferido recurrir ocasionalmente al servicio de otros religiosos ${ }^{18}$, entre ellos, del dominico fray Juan Hurtado de Mendoza, uno de los líderes del movimiento reformista en su orden religiosa y partidario de los imperiales durante la Guerra de las Comunidades ${ }^{19}$. Seguramente fue el mismo Juan Hurtado quien influyó en la elección de Loaysa como confesor real, hasta ese momento Maestro General de los dominicos.

fattegli, nè le può dimenticare così fácilmente», RELAZIONI DEGLI AMBASCIATORI VENETI AL SENATO, 1840: 62.

15 CAUCHIES, 2004: 121-130.

16 MARTÍNEZ MILLÁN, 2000: 222-223

17 «Le 21e à Valdolit jusques le 23e d'aougst. Au mesme temps et lieu revint la royne, vefve du roy du Portugal, soeur aisnée de Sa Majesté. Et en ce mesme temps fut faict confesseur de Sa Majesté Frère Loayse, général des Jacoppins, et depuis fut évesque d'Osme». COLLECTION DES VOYAGES DES SOUVERAINS DES PAYS-BAS, XII, 1874: 68.

18 El 14 de agosto de 1523 Martín de Salinas, embajador del infante Fernando le informaba que, «en lo que toca a decir le haga saber quién es confesor del Emperador, hasta agora S. M. se ha servido de prestado; de aquí adelante no sé quien será. Dos veces y las postreras se ha confesado con el General de los Dominicos, que es fr. García de Loaysa, colegial que fue un tiempo cuando Mosieur estuvo en el colegio; hánle hecho Arzobispo de Granada e Inquisidor mayor». RODRÍGUEZ VILLA, 1903: 131.

19 Como muestra de su confianza, el Emperador ofreció en 1522 el arzobispado de Granada y luego el de Toledo a fray Juan Hurtado. BELTRÁN DE HEREDIA, 1939: 152 y ss. LONGO, 1995: 427-430. 
Además, Adriano de Utrecht conocía personalmente a Loaysa, con quien se encontraba en Vitoria cuando recibió la noticia de su elección como papa. De todos modos, al elegir al general de los dominicos como confesor, el emperador reforzaba también su legitimidad, puesto que los monarcas de la Casa Trastámara, incluido Fernando el Católico, habían elegido comúnmente a los frailes predicadores para desempeñar ese oficio ${ }^{20}$.

\section{EL FRAILE DOMINICO}

García de Loaysa había nacido hacia 1478, era hijo del licenciado Pedro de Loaysa, señor de la Huerta, corregidor de Salamanca y regidor de Talavera de la Reina, y de Catalina de Mendoza. Al igual que sucedía con otros miembros de los linajes nobles de Talavera de la Reina, como los Ayala o los Álvarez de Toledo, los de la familia Loaysa se sucedían en el gobierno de la ciudad desde principios del siglo $\mathrm{XV}^{21}$.

A una edad muy temprana, probablemente en 1492, García ingresó en el Convento de San Esteban de Salamanca. Dicha decisión estuvo condicionada por dos situaciones. Por un lado, porque su madre, ya viuda, se hallaba en aprietos económicos, puesto que cargaba con el pago de unas multas de su difunto marido, cobradas a causa del juicio de residencia que en 1490 había ordenado Isabel la Católica que se realizara a Pedro de Loaysa por su desempeño como corregidor de Salamanca ${ }^{22}$. El segundo motivo era que en el convento salmantino se hallaba uno de sus hermanos, fray Domingo de Mendoza, quien había profesado anteriormente ${ }^{23}$.

Si bien allí vistió el hábito de fraile de coro, la disciplina severa que se practicaba durante el priorato del reformista Antonio de la Peña afectó su

20 Si bien es cierto que a lo largo del siglo XV no monopolizaron el confesionario regio, la mayoría de los confesores de los reyes y reinas de esa dinastía fueron dominicos. Situación particularmente excepcional si se considera que en otras monarquías, como la inglesa o la francesa, dejaron de servir a los reyes en ese oficio a finales del siglo XIV. En Francia fueron privados de ese cargo a causa de la controversia sobre la Inmaculada Concepción que había desatado allí fray Juan de Monzón y en Inglaterra, tras la destitución de Ricardo II, los Lancaster prefirieron servirse de confesores carmelitas. NIEVA OCAMPO, 2012: 525-541; LA SELLE, 1995: 104-105; RÖHRKASTEN, 2004: 214-216; GOÑI GAZTAMBIDE, 1980: 506523.

21 PACHECO JIMÉNEZ, 1998: 44-53; GÓMEZ-MENOR FUENTES, 1989: 353-380.

22 Archivo General de Simancas, Registro General del Sello, Leg. 149204, 256; Leg. $149201,36$.

$23 \mathrm{Su}$ hermano mayor era Alonso Jofre de Loaysa quien tuvo descendencia, el siguiente era Domingo de Mendoza fraile dominico, seguía García y finalmente Pedro, que murió a temprana edad. Además tuvo una hermana, Inés de Loaysa. Tabla genealógica de la Casa de Loaysa, señores de Huerta. Real Academia de la Historia, Colección Salazar y Castro, 25, f 36. 
constitución delicada y tuvo que ser destinado al Convento de San Pablo de Peñafiel, donde finalmente realizó su profesión religiosa un año después ${ }^{24}$. A continuación, fray García completó sus estudios de filosofía y teología en el Convento de Santo Tomás de Avila y más tarde, durante siete años, en el Colegio de San Gregorio de Valladolid. Casi al mismo tiempo fue nombrado regente de estudios en el Colegio vallisoletano, donde además recibió el grado de maestro de Teología. Tal como señala fray Juan de la Cruz, «luego fue elegido prior de Ávila, y dentro de un año de Valladolid, y luego definidor del Capítulo Provincial, y luego del general, y luego Vicario de su provincia, y luego Provincial: el qual officio administró con exemplo de religión y humildad, visitando la provincia en un asnillo pobre» ${ }^{25}$.

En 1518 representó a su provincia en el Capítulo General celebrado en Roma, donde fue elegido Maestro General de la Orden de los dominicos, sucediendo a Tomás de Vio Cayetano ${ }^{26}$. Durante los dos primeros años de su generalato realizó una visita de reforma a los conventos de Nápoles y Sicilia, y luego pidió licencia al papa León X para retirarse de su corte durante dos años, con el fin de celebrar capítulo general en Valencia y previamente para visitar los conventos de las provincias ibéricas. Llegó a Valladolid, después de visitar Navarra y Burgos, a principios de noviembre de 1520.

Su regreso a Castilla coincidió con el estallido de la revuelta comunera. Tal como señala fray Juan de la Cruz, durante el conflicto Loaysa, «por su natural bondad y suavidad que de fuera se mostraba, y por la gravedad, y prudencia, y viveza de ingenio con que trataba todos los negocios», se preocupó por mediar como pacificador $\mathrm{y}$, sobre todo, por demostrar su adhesión a la causa imperial, puesto que en su misma orden religiosa, «unos favorecieron en sus sermones las partes del legítimo Rey, y refrenaban a los pueblos y ciudadanos de su desatino; otros seguían y ayudaban con sus palabras y consejos y públicos sermones a las comunidades».

El superior de los dominicos aparece en enero de 1521 como mediador entre el rey y la Comunidad de Valladolid, junto al nuncio apostólico y al embajador de Portugal ${ }^{27}$. Sin embargo, el éxito más sonado de su intervención lo logró cuando convenció a Pedro Laso de la Vega, procurador de Toledo y uno de los cabecillas de la rebelión, a que renunciase al bando rebelde e incluso para que éste convenciese a otros insurrectos a hacer lo mismo 28.

A partir de la derrota de los Comuneros en la batalla de Villalar se había dado inicio a la represión de los rebeldes. Gracias a la intervención del carde-

24 MINGUELLA Y ARNEDO, 1912: 222.

25 CRUZ, 1567: 131v.

26 Sobre su desempeño como general de los dominicos véase MORTIER, 1911: 231-259.

27 PÉREZ, 2005: 284.

28 SANDOVAL, 1604-1606: 110-120. 
nal Adriano de Utrecht, quien consideraba que con un castigo a los frailes que habían participado a favor de los comuneros «será edificado todo el mundo», fray García de Loaysa había logrado que en el mes de julio de 1521 le fuera encargada la sanción de los culpables entre los dominicos ${ }^{29}$.

El cronista Sebastián Olmeda, asegura que Loaysa privó de sus títulos a cuatro maestros en teología condenándolos a continuación a la prisión ${ }^{30}$. Los cuatro frailes corresponden a los que habían sido exceptuados del perdón general: fray Alonso de Bustillo, fray Pablo de León, fray Alonso de Medina y fray Antonio de Villegas.

Por otro lado, el maestro general visitó la comunidad dominica más influyente del reino de Castilla, el Convento de San Esteban de Salamanca, cuyos frailes estuvieron muy comprometidos con la rebelión. Allí promulgó una serie de ordenaciones para su reforma ${ }^{31}$. Lo hacía porque consideraba, al igual que muchos contemporáneos, que ese convento estaba obligado «a ser con eficacia modelo y ejemplo de vida regular y de santa conversación en toda la provincia [...] para hacer honor a su nombre y a su fama, y ya que es sementera fecunda que germina en toda la provincia». Fray García estaba convencido que esa acción debía cerrar una etapa y limpiar de la memoria colectiva toda vinculación de los frailes con los hechos recientes, de ahí que mandase al superior del convento que hiciera observar escrupulosamente a los religiosos las constituciones de la Orden y las costumbres de la Provincia «y, para que el silencio se mantenga para siempre, ordeno que este apartado se lea con frecuencia ${ }^{32}$.

En 1522 García de Loaysa, que desde el 20 de febrero de ese año hasta el 10 de septiembre del año siguiente ejercía también como presidente de las Inquisiciones de Castilla y de Aragón, aprovechó la reunión del Capítulo de

29 «Oy avemos visto en el Consejo dos traslados de dos provisiones que agora nuevamente an dado los governadores; la una dieron el almirante y condestable; la otra el cardenal solo. Lo que contienen es que todos los frayles de la orden de Santo Domingo que an sido principales traydores de todos estos reynos sean remitidos al general de su orden, que es otro tanto como mandarlos soltar, para que tornen a predicar antes de muchos días. Aquí teníamos preso a uno muy principal dellos y se llama maestro Bustillo; el cardenal manda que lo den al general y será para que le suelte $u$ esto haze el cardenal como comisario apostólico. Todos los del Consejo estamos desesperados en ver estas provisiones y otras tales». Carta al emperador, 6 de agosto de 1521. Archivo General de Simancas, Estado, leg. 8, f. 117.

30 «Damnavit, proinde, post hujusmodi Communitatum ruinam, Salmanticae constitutus Garsias idem quatuor ex majoribus, qui omnes in Theologia doctoratus gradu insigniti famaque notissimi sunt habiti. Unus etiam Regalis Curiae Praedicator aliusque Valleoletani Theologicae cathedrae Rector; omnes enim, Magisterio oficiisque privati ac carceri sunt adjudicati», OLMEDA, 1546:109.

31 Las Ordenaciones del Maestro general García de Loaysa han sido publicadas por HERNÁNDEZ, 1996: 5-13.

32 HERNÁNDEZ, 1996: 5-13. 
los dominicos que se celebraba en Salamanca para promover la elección de un provincial leal al emperador. Por ello desconoció la elección como prior provincial de fray Bernardo Manrique ${ }^{33}$, quien como superior del Convento de San Esteban había favorecido la causa comunera, y forzó en su lugar el nombramiento de fray Diego Pineda, fraile del Convento de Santo Domingo de Piedrahita ${ }^{34}$. Las prescripciones que se dictaron a continuación concedían al nuevo provincial un amplísimo poder para que dispensase e interpretase las disposiciones capitulares a su voluntad y según su prudencia.

El núcleo central de las actas del Capítulo de Salamanca de 1522 lo constituyen las ordenaciones de García de Loaysa. En ellas el maestro general ordenaba la adhesión y el respeto de los frailes a la autoridad del emperador:

Se debe honrar con la correspondiente veneración en todo lugar a toda potestad terrena, cuanto más debe hacerse con el tan católico, respetuoso y justísimo nuestro César Carlos. A él amparan y sostienen la justicia, la paz, la misericordia y la verdad. $\mathrm{Y}$ en grado máximo es honrado por los predicadores de la palabra divina, por los que el pueblo es iluminado y dirigido ${ }^{35}$.

Asimismo, se reforzaban los poderes de los superiores conventuales en materia disciplinar sobre sus súbditos, se impedía a los frailes el acceso directo a la Corte, se proponía un tipo de formación más cuidadosa y vigilante de los jóvenes mediante la elección de formadores experimentados y se prohibía el estudio, antes de cumplir el año de profesión, en otra facultad que no fuera la de Gramática.

Loaysa criminalizó y penalizó duramente la participación de los religiosos en las Comunidades, ordenando «que en la provincia haya algunas cárceles en ciertos conventos, en las cuales sean custodiados diligentísimamente los condenados por excesos, que en un juicio civil serían castigados con la pena de muerte y que sean los conventos siguientes: los de Salamanca, Ávila, Toledo,

33 Era hijo del primer marqués de Aguilar, don García Fernández de Manrique Para algunos sería el segundogénito del matrimonio de Fernández de Manrique con su esposa doña Brazaida de Almada, dama de la reina Juana de Portugal. Sin embargo, es más seguro que fuera un hijo extramatrimonial del marqués. MENDOZA Y BOBADILLA, 1560: 141; LÓPEZ DE HARO, 1622: 178.

${ }^{34}$ Las actas capitulares no transmiten los motivos de esa decisión, que sembró la perplejidad en los mismos historiadores de la Orden. MORA, 1730: 991-993. Pineda fue elegido provincial por mayoría de un voto. Sebastián Olmeda, que estaba presente, se muestra contrariado por la actuación del Maestro General: «Salmanticae electionem cuiusdam in provinciales, praesens ipse in Capitulo et ad banchum, extra constitutionis tenores, sedes, nulla assignata causa, cassavit, alteriusque ex continente, cunctis silentio imposito, magnaque adhibida, unius tantum vocis excessu factam, confirmavit. Qui vidit enim testimonium perhibet», OLMEDA: 203.

35 HERNÁNDEZ, 1998: 6-25. 
Burgos y Compostela $»^{36}$. Además, encargaba a Pineda la encarcelación de los frailes criminales. Asimismo, ordenó «a los priores de esos conventos que en el espacio de seis meses determinen con el consejo de los Padres los lugares convenientes para esa clase de cárceles y las provean bien de cadenas y de las otras cosas que necesiten». La preocupación del prelado por todo lo sucedido lo llevó a dictar medidas preventivas, entre ellas, dispuso que los priores, después del almuerzo, «hagan reunir a los frailes en el capítulo o en otro lugar conveniente, y tengan alguna conferencia sobre los casos de conciencia, al menos por media hora».

En fin, gracias a la veloz actuación de fray García de Loaysa y también a la admiración que el Condestable don Iñigo de Velasco sentía por fray Pedro de Cobarrubias y, sobre todo, por fray Juan Hurtado de Mendoza, la Orden de Santo Domingo recuperó inmediatamente su crédito ante el emperador. Muestra de ello es que en 1523 Carlos V se preocupó por favorecer a los superiores dominicos que habían actuado a favor de los imperiales durante el conflicto de las Comunidades. A fray Juan Hurtado dió el arzobispado de Granada, que no aceptó; el obispado de Córdoba a fray Juan Álvarez de Toledo, hijo del duque de Alba, y el de Osma al maestro general fray García de Loaysa $^{37}$.

Martín de Salinas, embajador de Fernando de Habsburgo, informaba a su señor acerca de la situación del confesor real y de los cambios que se habían verificado en el episcopado castellano:

A su compañero el Arzobispo de Granada [Antonio de Rojas y Manrique] daban el de Burgos, y con gran pensión, y no lo quiso aceptar; a la cual causa lo dieron al Obispo de Osma [Juan Tavera], que era Presidente de la Chancillería de Valladolid, sobrino que era del Arzobispo de Sevilla pasado [Diego de Deza], y le habían dado el obispado de Osma por vacación de su hermano del Almirante y diz que con seis mil ducados de pensión para dar a Don Jorge, y con otros tres mil que tiene, serán nueve mil, de suerte que responde a un buen obispado. El Arzobispado de Granada daban al Confesor de S. M., General de los Dominicos, y por le parecer tener con él mucho trabajo y poca renta no lo quiso acetar, y agora toma el de Osma ${ }^{38}$.

Finalmente, tras largas negociaciones, en agosto de 1524 Antonio de Rojas fue nombrado obispo de Palencia y Pratriarca de las Indias,

36 HERNÁNDEZ, 1998: 6-25.

37 Antes de renunciar a su cargo de Maestro General de los dominicos, Loaysa reunió un Capítulo General de la Orden en la ciudad de Valladolid. Una carta suya, que acompañaba a las actas de la reunión, muestra su interés por continuar la reforma de la Orden, al condenar la propiedad privada entre los frailes y promover la vida comunitaria. ACTA CAPITULORUM GENERALIUM, 1901: 179-180

38 RODRÍGUEZ VILLA: 168. 
y como hubiese tres años que estuviese la iglesia de Toledo vaca la dio Su Majestad este año a D. Alonso de Fonseca, Arzobispo que era de Santiago; y en el Arzobispado de Santiago presentó a D. Juan Tavera, que era obispo de Osma y Presidente del Consejo Real; y el Obispado de Osma dio a Fray García de Loaysa, Presidente del Consejo de Indias, hijo del Licenciado Loaysa, natural de Talave$\mathrm{ra}^{39}$.

\section{CONFESOR Y CONSEJERO}

Las ordenaciones de la Grande Chapelle ${ }^{40}$, aprobadas por Carlos cuando aún era archiduque, consideraban que ese organismo no sólo se encargaba de prestar servicios litúrgicos al soberano y de dar limosnas en su nombre, sino que era una comunidad de clérigos organizada jerárquicamente, que debía reunirse semanalmente en capítulo para corregir las faltas de sus miembros. A la cabeza de dicha organización estaban los capellanes mayores y por encima de ellos el confesor real, encargado de velar por la disciplina del organismo en caso de negligencia de los capellanes ${ }^{41}$.

El embajador veneciano Gasparo Contarini constataba en 1525, cuando García de Loaysa ejercía ya como confesor del emperador, que la Capilla conservaba esa estructura:

Tiene ordinariamente sua maestà quaranta cappelani con due scudi al mese per uno, e sono secondogeniti dei principali personaggi de'suoi stati; li quali avendo

39 SANTA CRUZ, 1551: 98.

40 COLLECTION DES VOYAGES DES SOUVERAINS DES PAYS-BAS, 1874: 495-496.

41 Esta institución habría tenido hasta principios del siglo XVI una historia bastante discontinua, ligada al destino de los duques de Borgoña: «The Burgundian chapel superficially seems to fulfil the majority, if not all, of the conditions of an 'institution', as defined above (statutes, image, continuity and repertory). However, the discontinuity and ambiguities of the history of this chapel are not difficult to identify, and reseachers have in fact already done so. Such discontinuity and imprecision, first and foremost, affected the chapel's very existence: for example, in 1404 John the Fearless, dissolved it and it was not refounded until 1415. Second, these factors affect its location, a logical consequence of itinerant courts. In practice, this chapel was based not in Dijon, the Burgundian capital, but preponderantly in Brussels, Paris and Liège. Third, they affect the repertory itself, which is difficult to associate with the history of the chapel. The chapel's very identity becomes problematic from 1477 onwards, following the death of Charles the Bold, when it was inherited by Maximilian I, who owned it until Philip the Fair came of age in 1494. Significantly, in 1490 Maximilian seems to have had three different chapels at his disposal: his own chapel in Innsbruck, the Burgundian chapel, and the one that Emperor Frederick III had founded while residing in Vienna-Neustadt. But the story became even more complicated. Part of the Burgundian chapel that had accompanied Philip the Fair regrouped under the regency of Margaret of Austria in Mechelen, later forming the chapel of Archiduke Charles in 1509, which would accompany him to Brussels in 1515 and from there to Spain two yers later», CARRERAS LÓPEZ, 2005: 16. 
servito sei, otto, dieci e più anni sono remunerati con pensioni, abadie, e vescovadi, sì come pare a sua maestà; e questi sono tenuti andare in capella con le loro cotte, e cantare i vespri come preti privati. Vi è l'elemosinario, il quale oltra l'uffizio suo di dispensare l'elemosina (circa mille scudi l'anno) serve anco di mastro di cerimonie nella capella, e sta sempre al baldacchino di sua maestà, avvertendola quando debbe levarsi e quando inginocchiarsi, e quando andaré all'offerta, mostrandogli sopra certi libri e messali l'orazione, e tutto quello che si dice alla messa. Vi sono cantori, forse al numero di quaranta, la più compiuta ed eccelente cappella di cristianità, eletta di tutti li Paesi-Bassi, che sono oggi dì il fonte della musica. Son vi poi inferiori ministri deputati al coro, alli libri di canto, al baldacchino di sua maestà e altri ornamenti della cappella, con bell'ordine e molta regola. Vi sono due predicatori, uno francese, l'altro spagnolo; e tutti questi sono sotto il confessore, il quale ordinariamente è frate di san Domenico dell'osservanza, e ha dugento scudi al mese per sue spese, e qualche altro donativo straordinario per spese pie ${ }^{42}$.

\section{A su vez, Contarini reconocía que el poder del confesor real excedía el ámbito de lo litúrgico:}

Questo confessore entra in tutti i consigli dove si trattino cose pertinenti alla conscienza; e per questo viene ammesso dove si parla di guerra e di giustizia, e principalmente quado si denunziano e consultano le denominazioni dei benefizj: il qual confessore suol quasi sempre riuscir vescovo, e quealche volta cardinale, e méritamente, perchè prometto a vostra serenità que ha un carico grandissimo a parlare e quasi a risolvere circa le cose d'eretici, di cristiani nuovi di Spagna, di Mori, d'usure, di guerra contro cristiani e infedeli, di benefizj, di concilj, e quasi di tutte le cose che faccia l'imperatore, perchè tutte concernono la conscienza; e in questo bisogna ch'egli con desterità non manchi di dire l'opinion sua fondatamente e con buona ragione, e vegga di dirla così modestamente che sia accettata la verità senza disgrado della sua modestia, altramente esso faria poco frutto e scemeria l'autorità sua infinitamente ${ }^{43}$.

En efecto, hacia 1525 todas las cuestiones de Estado vinculadas a la conciencia del monarca, desde los casos de herejía a la declaración de guerra contra príncipes cristianos o infieles, pendían de la opinión del confesor real. Además, ésta se hacía sentir en la provisión de beneficios y en casi todos los asuntos de Consejo.

Y es que García de Loaysa intervino en los asuntos de gobierno desde el mismo momento que se integró a la Corte como confesor ${ }^{44}$. De hecho, el 15

42 RELAZIONI DEGLI AMBASCIATORI VENETI AL SENATO, 1840: 207-208.

43 RELAZIONI DEGLI AMBASCIATORI VENETI AL SENATO, 1840: 208-209.

44 Sebastián Olmeda señala el cambio que se produjo en la personalidad de Loaysa desde que comenzó a ocupar cargos en la corte, abandonando las observancias y austeridades que hasta ese momento lo caracterizaban como un dominico reformado. Véase, OLMEDA, 1546: 202-203. 
de julio de 1524 , frente a la necesidad del emperador de sellar una alianza con los portugueses, con quienes se discutía la posesión de las Molucas ${ }^{45}, \mathrm{y}$ ante la imposibilidad de que se casase con una princesa lusitana, puesto que ya estaba comprometido con la hija del rey de Inglaterra, María Tudor, Loaysa propuso la boda de la hermana menor de Carlos V, Catalina, con el rey Juan III de Portugal. La infanta vivía en Tordesillas, junto a la reina Juana, y estaba libre de compromisos anteriores ${ }^{46}$. La solución fue aceptada inmediatamente y cuatro días después se firmaron las correspondientes capitulaciones con los embajadores del monarca portugués. En agosto el confesor real obtenía el báculo de obispo de Osma y era consagrado en una fastuosa ceremonia con la presencia de toda la Corte.

Junto a la promoción al episcopado, Loaysa consiguió también la presidencia del recién creado Consejo de Indias, a pesar que su nombre no figuraba entre los que se habían propuesto desde principios de aquel año para desempeñar ese oficio ${ }^{47}$. En efecto, tras acordar en Burgos el matrimonio de Catalina con el rey de Portugal, Carlos V visitó a su madre en Tordesillas y el 4 de $\operatorname{agosto}^{48}$,

estando el emperador en Valladolid, hizo Presidente del Consejo de Indias a don García de Loaysa, fraile de la Orden de Santo Domingo y general de la dicha Orden, su confesor, el cual era ya Obispo de Osma, y puso por Oidores del dicho consejo a don Luis Vaca, Obispo de Canarias, y al doctor Beltrán y al doctor Maldonado, y mandó a Pedro Mártir que asistiese en el dicho Consejo por Cronista de las cosas de las Indias ${ }^{49}$.

A partir de entonces, muchos observadores reconocieron la creciente influencia que, junto a Francisco de los Cobos, ejercía en la Corte el confesor real. De hecho, en diciembre de 1524, Martín de Salinas escribió al Tesorero de Salamanca: «El confesor de S.M. va subiendo a más andar y querría que S.A. [don Fernando] hiciese alguna cuenta dél». En la primavera de 1525, escribió dos veces insistiendo para que Fernando de Habsburgo cultivase el favor de Cobos y del confesor ${ }^{50}$.

45 Desde el mes de abril de 1524 se había conformado una Junta de expertos y diplomáticos que se reunió con sus correspondientes de Portugal en la frontera de Badajoz. Sobre el tema véase, SÁNCHEZ, 1993: 57-61.

46 Archivo General de Simancas, Estado, 8-143.

47 En realidad, se había propuesto para ese cargo al doctor Manso, obispo de Guadix, cuya candidatura fue desestimada. BELTRÁN DE HEREDIA, 1970: 499-500.

48 CADENAS Y VINCENT, 1992: 159; COLECCIÓN DE DOCUMENTOS INÉDITOS RELATIVOS AL DESCUBRIMIENTO, 1923: 24.

49 SANTA CRUZ, 1551: 98.

50 KENISTON, 1980: 86-87. 
En ese año Loaysa participó en diversas juntas reunidas para tratar los asuntos más dispares. De ese modo, fue convocado a la junta reunida por Carlos V para discernir el destino de Francisco I y las condiciones de su prisión, dando una opinión favorable a la liberación del rey francés ${ }^{51}$. Igualmente, en 1525, asistió a la junta que se celebró en Madrid para tratar sobre la persistencia de prácticas religiosas musulmanas entre los moriscos de Valencia y para deliberar sobre la validez de los bautismos, en caso de que estos se hubiesen forzado. Dos años antes, García de Loaysa, como inquisidor interino, había ordenado que las mezquitas convertidas en iglesias continuaran dedicadas al culto cristiano y había dispuesto que una comisión estudiase la validez de los bautismos. El nuevo inquisidor general, Alonso Manrique, arzobispo de Sevilla, hizo suyo el proyecto de la junta y lo propuso al emperador el 23 de enero de 1524. Carlos V aceptó la idea y unos días después cursó órdenes para que se reuniese la asamblea en la que participó el confesor. A principios de 1525, la junta dictaminó que los bautismos eran válidos por no haber intervenido fuerza ni violencia. En consecuencia, se dispuso el envío de predicadores para catequizar a los moriscos ${ }^{52}$.

En 1526 nuevamente se presentó el problema morisco al residir la corte en Granada, en oportunidad de la visita a Andalucía del emperador, tras su matrimonio con Isabel de Portugal. Las quejas del maltrato que recibían los moriscos granadinos y, a su vez, las denuncias de que éstos practicaban el Islam condujeron a la constitución de la célebre Congregación de la Capilla. En esa junta, reunida por orden del rey, intervinieron varios miembros de la anterior junta madrileña, entre los que se encontraba el confesor García de Loaysa ${ }^{53}$. Los acuerdos suscriptos y promulgados por el emperador conllevan una sustancial reorganización eclesiástica de la archidiócesis, que descansaba en la autoridad disciplinaria del prelado, en aquel momento don Pedro de Alba, quien debía visitar su jurisdicción eclesiástica y organizar sínodos con el fin

51 GONZÁLEZ DÁVILA, 1618: 65.

52 GOÑI GAZTAMBIDE, 2007: 209-216.

53 «Para remedio, pues, de tan gran mal mandó el emperador que se juntasen algunos Letrados y Prelados de su Corte para que viesen los procesos y relaciones que los Visitadores traían, y conforme a ellos diesen alguna orden en las cosas de aquel Reino, mediante la cual se remediase el mal pasado y se descargase su conciencia, y a esta se juntaron por espacio de muchos días en la capilla Real D. Alonso Manrique, arzobispo de Sevilla e Inquisidor General, y D. García de Loaysa, obispo de Osma, confesor del Emperador, y D. fray Pedro de Alba, arzobispo de Granada, y D. Gaspar de Ávalos, obispo de Guadix, y D. fray Diego de Villalar, obispo de Almería, y D. Juan [Jerónimo] Juárez, obispo de Mondoñedo [en realidad no asistió, según Benítez Sánchez-Blanco], y D. Alonso [Fernando] Valdés, obispo de Orense, y D. García de Padilla, Comendador mayor de Calabrava, y Francisco de los Cobos, Secretario de Su Majestad, y el Doctor Guevara, del Consejo Real, y los visitadores dichos que habían ido a visitar el Reino». SANTA CRUZ: 246-247. 
de garantizar la idoneidad de los clérigos. Se legislaba, entre otras cosas, acerca de la gratuidad de la administración de los sacramentos y la edificación de las iglesias. Como complemento de la acción del clero secular, se ordenaba la fundación de comunidades de dominicos y franciscanos, quienes debían ayudar en las tareas evangelizadoras. Este último punto estaba vinculado al tipo de predicación, que debía ser sencilla y estar centrada en la refutación de la doctrina mahometana, práctica en la que los frailes eran considerados expertos. Para controlar la conducta religiosa de los moriscos y asistir en la tarea disciplinar de los obispos, se introducía el Santo Oficio. Al igual que en Valencia, en buena medida estas normas no pudieron aplicarse ${ }^{54}$.

\section{LOAYSA Y EL GOBIERNO DE NUEVA ESPAÑA}

Es sobre todo en los asuntos de Indias donde queda al descubierto el notable entendimiento que existía en la Corte entre García de Loaysa y el secretario Francisco de los Cobos. De hecho, se puede considerar que el confesor real secundaba la política clientelar de Cobos en el Nuevo Mundo, tal como se observa en los conflictos que enfrentaron a Hernán Cortés y sus partidarios por un lado, con las autoridades enviadas por el emperador a partir de 1525 por otro, estos últimos clientes del secretario real. Paralelamente a ello, se desarrolló un conflicto eclesiástico, dilatado en el tiempo por el mismo Loaysa, que tenía como protagonistas a los religiosos encargados de evangelizar las nuevas tierras conquistadas, consecuencia en buena medida de un sordo enfrentamiento en el interior de las filas de los dominicos, entre aquellos que se habían instalado en México y provenían de las islas del Caribe, donde habían llegado hacia 1510, y los que venían directamente de la Península enviados por el Presidente del Consejo de Indias, contrarios a Cortés y favorables a los clientes de Cobos.

Efectivamente, desde mediados de 1518 Francisco de los Cobos, que disfrutaba del favor del líder del partido flamenco en la Corte de Carlos I, el señor de Chièvres, ejercía como secretario de Indias en el Consejo de Castilla ${ }^{55}$. Desde ese cargo y amparado también por Rodríguez de Fonseca, consejero mayor en los asuntos de Indias, logró trabar amistad con Diego Velázquez de Cuéllar, gobernador de Cuba, a través del cual comenzó a participar de lleno en el negocio indiano, puesto que en 1519 Cobos no sólo obtenía el gobierno y adelantamiento sobre Yucatán, sino también el cargo de fundidor y marcador sobre esa región recién conquistada, con el derecho al uno por ciento del me-

54 BENÍTEZ SÁNCHEZ-BLANCO, 2001: 415-446.

55 KENISTON: 44-47. 
tal ensayado y acuñado ${ }^{56}$. El objetivo del secretario real en los años siguientes fue la extensión de ese privilegio a otras regiones americanas, asunto de una gran relevancia, si se piensa que los territorios que se conquistaron e incorporaron a la Corona a partir de entonces aportaron un enorme tesoro metalífero. De hecho, poco tiempo después, el 16 de mayo de 1522, obtenía del emperador el nombramiento como fundidor mayor de la Nueva España ${ }^{57}$.

Por entonces, el clérigo Bartolomé de las Casas, quien había sido nombrado por el cardenal Cisneros Protector universal de los indios, acusaba en la corte al grupo liderado por Fonseca, del que formaba parte Cobos, de los desmanes cometidos por los españoles contra los indígenas en el Caribe. De esas acusaciones se hizo eco el canciller Jean Sauvage y, tras su muerte, su sucesor Mercurino de Gattinara. Fue a este último, quien se oponía a las intenciones del partido flamenco, a quien le tocó en octubre de 1522 presidir la comisión encargada de estudiar el enfrentamiento entre Hernán Cortés y Diego Velázquez de Cuéllar en las Indias, fallando a favor de Cortés:

Por sentencia que dieron estos señores, y porque se lo aconsejaron assi, hizo el emperador a Fernando Cortes adelantado, repartidor y gobernador de la nueva España, y quantas tierras ganasse, loando y confirmando todo lo que avia hecho en servicio de Dios y suyo [...] Notificaron la sentencia a Diego Velázquez, con publico pregon en Santiago de Barucoa de Cuba el mayo adelante de veynte y tres años. De lo qual sintió tanto pesar Diego Velazquez, que vino a morir dello ${ }^{58}$.

De ese modo, la posición de Cobos y de sus criaturas se veía sumamente afectada en las Indias, puesto que Gattinara se había encargado de transformar a Cortés en el árbitro de la situación. A su vez, el mismo canciller aspiraba a convertirse en árbitro de los grupos enfrentados en la corte ${ }^{59}$.

No obstante, en el contexto de una gran reforma en los órganos de gobierno de la Monarquía, a mediados de 1524 el emperador nombró presidente del Consejo Supremo de Indias a fray García de Loaysa, tal como hemos dicho, y secretario del mismo Consejo a Francisco de los Cobos, arruinando con ello las expectativas del canciller Gattinara, interesado en controlar la administración castellana e indiana ${ }^{60}$. A partir de entonces Loaysa y Cobos se encargarían

56 KENISTON: 53.

57 KENISTON: 70.

58 LÓPEZ DE GOMARA, 1554: 238v-239v.

59 RIVERO RODRÍGUEZ, 2005: 98.

60 Gattinara se había visto también excluido del Consejo de Hacienda, fundado el año anterior, mientras que también allí eran introducidos Cobos y su ayudante Sancho de Paz. De hecho, Cobos era secretario de todos los consejos, excepto de los de Aragón, Órdenes y Guerra. Por otro lado, el nombramiento de Loaysa también servía para contrapesar la creciente influencia que ejercía en el gobierno castellano Juan Pardo de Tavera, arzobispo de Santiago, 
de estorbar el gobierno de Cortés en Nueva España, con el fin de aumentar su propia influencia en los negocios americanos.

Unos meses antes, Carlos V había enviado a México a los oficiales reales que debían acompañar a Cortés en su gobierno: Alonso de Estrada, tesorero, que había sido contino de la Casa real; Rodrigo de Albornoz, contador; Gonzalo de Salazar, factor; y Pedro Almíndez Chirino, veedor. Los dos últimos eran criados de Cobos ${ }^{61}$.

La partida de Hernán Cortés de la ciudad de México, en octubre de 1524, para realizar la expedición a las Hibueras, le obligó a dejar a Estrada y a Albornoz al frente del gobierno; pero como éstos terminaron enfrentándose, determinó que ejercieran el mismo junto a Salazar, a Chirino y al licenciado Alonso Zuanzo, investido como Justicia Mayor. Tal como señala el cronista López de Gomara: «deste poder secreto que Cortés les dio a buen fin, resultó gran odio, y revueltas entre los oficiales del rey. Y nació una guerra civil, en que murieron hartos españoles, y estuvo México para perderse» ${ }^{62}$.

De hecho, Salazar y Chirino depusieron a Estrada, a Albornoz y a Zuanzo. A continuación, se hicieron con el gobierno, confiscaron los bienes de Cortés y comenzaron a hostigar e incluso a asesinar a los parientes y deudos del conquistador. Esta situación se mantuvo hasta principios de 1526, cuando por indicación de Cortés, sus partidarios nombraron a Estrada como teniente de gobernador y éste pudo apresar al factor y al veedor. De todos modos, Salazar y Chirino habían logrado enviar dineros al rey y cartas a Cobos en las que referían el desgobierno de la Nueva España. De allí que en el mes de julio llegase a la ciudad de México el licenciado Luis Ponce de León, otro criado del secretario real, con el cometido de proceder a realizar juicio de residencia a Hernán Cortés, quien perdía, de ese modo, su cargo de gobernador ${ }^{63}$.

Ponce de León, quien murió de modorra al poco tiempo de hacerse cargo del gobierno de México, dejó como sucesor a su secretario, Marcos de Aguilar, quien también murió de fiebres tropicales a principios de 1527. Entonces se hizo cargo del gobierno Alonso de Estrada, quien, enemistado con Cortés, liberó de la prisión a Chirino y a Salazar y mandó al destierro, a Tlaxcala, al conquistador de México.

Luis Ponce de León no había llegado solo a México, lo hizo junto a fray Tomás Ortiz, superior de los dominicos enviados por Loaysa en respuesta a

que desde 1523 ocupaba la presidencia de la Chancillería de Valladolid y desde el año siguiente la presidencia del Consejo de Castilla. KENISTON: 78, 79.

61 LÓPEZ DE GOMARA, 1554: 280v.

62 LÓPEZ DE GOMARA, 1554: 246v.

63 CEDULARIO INDIANO, 1945: 186. 
un pedido que había realizado el mismo Hernán Cortés ${ }^{64}$. En efecto, para Cortés, como para numerosos conquistadores, el anuncio del cristianismo a los indígenas americanos y el sometimiento político al rey de los españoles y emperador del mundo legitimaba la conquista militar ${ }^{65}$. En su Cuarta Carta de Relación, del 15 de octubre de 1524, había pedido a Carlos V que enviase frailes franciscanos y dominicos, y no dignidades eclesiásticas:

que Vuestra Sacra Majestad mande que vengan a estas partes muchas personas religiosas, como ya he dicho, muy celosas de este fin de conversión de estas gentes y que de estos se hagan casas y monasterios por las provincias, que acá nos pareciere que conviene, y que a estas se les dé de los diezmos, para hacer sus casas y sostener sus vidas, y lo demás que restaren de ellos sea para las iglesias ornamentos de los pueblos, donde estuvieron los españoles, y para clérigos que los sirvan [...] Porque habiendo obispos y otros prelados no dejarían de seguir la costumbre que, por nuestros pecados hoy tienen, en disponer de los bienes de la Iglesia, que es gastarlos en pompas y en otros vicios, en dejar mayorazgos a sus hijos o parientes ${ }^{66}$.

Tal como relata fray Antonio de Remesal, fueron enviados en 1526 veinticuatro religiosos, doce franciscanos y doce dominicos. Entre los dominicos se contaban ocho procedentes de la Península, especialmente del Convento de San Esteban de Salamanca, y cuatro que se incorporaron en la Española durante el viaje a México. En la isla tuvieron que esperar esos religiosos a su superior, fray Tomás Ortiz, quien había sido convocado por Loaysa para tratar acerca de la legitimidad de la esclavitud de los indígenas americanos. Según López de Gomara, el parecer de Ortiz y del mismo Loaysa se inclinaba por la servidumbre de los indígenas, situación que ideológicamente los distanciaba del pensamiento de los franciscanos y de los mismos dominicos del Caribe, entre los que se contaba por entonces a Bartolomé de las Casas ${ }^{67}$. Lo cierto es que a finales del mes de julio los dominicos entraron en México, donde ya se encontraban los franciscanos. Fray Tomás de Ortiz había llegado antes, el 2 de julio, acompañando al licenciado Luis Ponce de León.

64 Desde 1508, el rey castellano gozaba del patronato sobre las iglesias de las Indias, lo que equivalía al derecho de fundación de diócesis y presentación de los obispos. A ello se agregó en 1522, por la bula Exponi Nobis, el derecho para organizar el envío de misioneros y la misma acción misional, concediéndose, a su vez, a los superiores de las Órdenes Mendicantes la autoridad episcopal, en todo lo que juzgasen conveniente para la conversión de las Indias, excepto el poder de ordenar.

65 FERNÁNDEZ RODRÍGUEZ, 1994: 91.

66 CARTAS DEL FAMOSO CONQUISTADOR HERNÁN CORTÉS, 1870: 525-526.

67 Domingo de Betanzos firmó un informe realizado por franciscanos y dominicos en septiembre de 1526 acerca de la necesidad de la encomienda, pero se trataba de una modalidad mitigada respecto a la que se había practicado en el Caribe. En ese sentido, apoyaban la solución aportada por Cortés. FERNÁNDEZ RODRÍGUEZ, 1994: 101. 
La expedición misional de los dominicos fue un fracaso desde el punto de vista pastoral, puesto que cinco frailes murieron de modorra y otros cuatro decidieron regresar a España en el mes de diciembre. Entre ellos estaba el mismo Tomás Ortiz, quien se encargó de desprestigiar en la Corte a Hernán Cortés, acusando al conquistador de haber asesinado al licenciado Ponce de León. Por su parte, Cortés escribió en enero de 1527 a Loaysa para defenderse de esas acusaciones y para acusar a su vez a Ortiz como difamador. De todos modos, el fraile nunca perdió la confianza del Presidente del Consejo de Indias, quien lo nombró en 1528 vicario de los dominicos que debían evangelizar la Gobernación de Santa Marta y al año siguiente consiguió para él el nombramiento de obispo de esa jurisdicción ${ }^{68}$.

Los pocos dominicos que quedaron en México, liderados por fray Domingo de Betanzos, uno de los dominicos proveniente de la Española, optaron por la práctica de la estricta pobreza comunitaria e individual, no admitiendo posesiones ni rentas y tampoco encomiendas de indios, contrariando con ello el querer del gobernador Estrada y también el pensamiento de García de Loysa, quien había aprobado en noviembre de 1527 la encomendación de los indígenas mexicanos ${ }^{69}$. De este modo, la austeridad de la comunidad de frailes predicadores comenzó a llamar la atención de los habitantes de la ciudad y a captar vocaciones religiosas.

Mientras tanto, Loaysa invitó a Hernán Cortés a venir a la Corte, prometiéndole su apoyo, con el fin de aclarar su situación ante el emperador ${ }^{70}$. En España, la llegada de Cortés a principios de 1528 coincidió con la designación de Mercurino de Gattinara como canciller de las Indias, quien había recuperado el favor imperial tras haber estado exiliado durante dos años en Italia ${ }^{71}$.

El conquistador recibió el título nobiliario de marqués del Valle y también logró realizar un matrimonio prestigioso con la sobrina del duque de Béjar. Sin embargo, sus poderes en el Nuevo Mundo se vieron sumamente mermados, ya sea porque el mismo Gattinara había promovido la creación de un gobierno para Nueva España más dependiente de la persona del rey, con la institución de la Primera Audiencia en diciembre de $1528^{72}$, o porque Fran-

68 En Santa Marta, fray Tomás Ortiz pronto entró en conflicto con el gobernador Pedro García de Lerma. FERNÁNDEZ RODRÍGUEZ, 1994: 108.

69 DISPOSICIONES COMPLEMENTARIAS DE LAS LEYES DE INDIAS, 1930: 8-12.

70 LÓPEZ DE GOMARA, 1534: 282v.

71 Según Rivero Rodríguez el Gran Canciller había dejado la Corte, tras comprobar que en 1526 no era el hombre de confianza del emperador y que los flamencos seguían dominando el gobierno, como en tiempos de Chièvres. RIVERO RODRÍGUEZ, 2011: 76.

72 Recientemente se ha visto en la creación de la Primera Audiencia el inicio de un gran programa virreinal para la Monarquía diseñado por el Gran Canciller, que culminaría en Nueva España en 1535 con el nombramiento de Antonio de Mendoza como virrey. RIVERO RODRÍGUEZ, 2011: 83 y ss. 
cisco de los Cobos y García de Loaysa habilitaron a clientes suyos para realizar la conquista de nuevos territorios en Centroamérica y en el Norte de Nueva España, aprovechando la ausencia de Cortés. Creo que en este sentido se debe leer el caso de Pedro de Alvarado, favorecido en 1528, por mediación de Francisco de los Cobos, con un hábito de la Orden de Santiago y con el título de Gobernador, Capitán General y Adelantado de Guatemala ${ }^{73}$. Asimismo, en 1528 Nuño de Guzmán, quien ejercía como gobernador de Pánuco, fue nombrado presidente de la Primera Audiencia.

Guzmán también era una hechura de $\operatorname{Cobos}^{74}$. Su relación había comenzado cuando el padre y los hermanos de Nuño - procuradores de Guadalajara en las Cortes de 1520 - habían apoyado el pedido de servicios por parte del rey para hacer frente a la elección imperial. En esa reunión Francisco de los Cobos actuaba como procurador de Granada y secretario de las Cortes. Por su mediación Nuño Guzmán fue nombrado contino del emperador. De ese modo, tuvo que acompañar a Carlos $\mathrm{V}$ en su viaje de coronación a Alemania. Estaba de vuelta en España en 1522 sirviendo al secretario real y por orden del rey ocupó y gobernó en 1523 la villa de Pareja, que estaba bajo jurisdicción del rebelde obispo de Cuenca, Diego Ramírez de Villaescusa. Entre 1524 y 1525 volvió a acompañar al emperador en sus desplazamientos por Castilla y en ese último año fue nombrado gobernador de Pánuco, territorio al norte de México, con el fin de limitar el poder de Cortés.

Partió a su nuevo destino en marzo de 1526, pero no llegó a él hasta mayo de 1527. Como gobernador se apresuró a impugnar a los encomenderos que en Pánuco había creado el conquistador de México. Debido a la falta de riquezas mineras en esa provincia autorizó la trata esclavista de la población nativa con destino al Caribe, negocio muy lucrativo, y también ocupó, a finales del 1527, algunos pueblos y territorios pertenecientes a Nueva España, premiando con encomiendas en esas tierras a sus propios seguidores, medida que lo enfrentó a los clientes de Cortés e incluso al gobernador Estrada a lo largo de 1528. En diciembre de ese año recibió el nombramiento de presidente de la Audiencia recién creada, justo cuando se preparaba para viajar a España.

En México, Nuño Guzmán repartió el gobierno entre la clientela que había creado en Pánuco. Asimismo, siguió expidiendo licencias para esclavizar indios, proceder que lo enfrentó con el obispo de México, Juan de Zumárraga, con los franciscanos y con algunos dominicos, pero no con todos. De hecho, una remesa importante de frailes enviados por Loaysa en agosto de 1528, bajo

73 Alvarado se había emparentado con Cobos, ya que éste había concertado su matrimonio con la ubetense Beatriz de Cueva, rompiendo el compromiso dado a Cortés de casarse con una hermana suya. REMESAL, 1619: 16-17.

74 Es de consulta obligada el estudio realizado por CHIPMAN, 2007. Véase además, MARTÍN TAMAYO, 1992. 
la dirección de fray Vicente de Santa María, admitía la entrega de indios tributarios, mientras que los franciscanos y los dominicos que seguían a fray Domingo de Betanzos eran contrarios a ello. De allí que Santa María apoyara la actuación de la Audiencia, obligando al obispo Zumárraga a pedir al rey, en diciembre de 1529, la reforma de esos frailes mediante el envío de visitadores provenientes de los conventos de las islas caribeñas: «a donde guardan la religión ad unguem en la Orden de Santo Domingo, y aquí no tanto» 75 .

La primera Audiencia de Nueva España se mantuvo hasta principios de 1531, pero la decisión de su suspensión estaba ya tomada el año anterior, justamente cuando García de Loaysa sufría el alejamiento de la Corte y su despido como confesor del emperador. De hecho, la posición de Loaysa se había debilitado desde que, a comienzos de 1528, fuera dado a Gattinara el título de canciller de las Indias ${ }^{76}$. A partir de ese momento el confesor no era convocado a las reuniones del Consejo de Estado y, además, corrían rumores acerca de su relevo en el confesionario regio. Por otra parte, desde la presidencia del Consejo Real, el arzobispo Tavera trataba de hacer extensiva su influencia al tratamiento de los asuntos indianos. Por lo tanto, el confesor contaba únicamente con el apoyo de Francisco de los Cobos cuando Carlos V marchó a Italia en 1529.

Loaysa acompañó al emperador en el viaje, pero después de recibir en Bolonia el capelo cardenalicio con título de Santa Susana, quedó agregado a la Corte romana. A ello unió Carlos V su nombramiento como obispo de Sigüenza en 1532. No obstante, parece evidente que el emperador únicamente buscaba un alejamiento honroso para el dominico. Sin embargo, no fue despojado de la presidencia del Consejo de Indias, por lo que, a pesar de su lejanía, siguió ocupándose de estos asuntos, aunque de manera muy limitada. Y si bien volvió a la Corte en 1533, nunca más volvió a ocupar el confesionario regio.

Entre los últimos servicios políticos de relevancia que prestó Loaysa, siendo confesor y consejero de Carlos V, figura la resolución del contencioso con los portugueses a causa de la propiedad sobre las Islas Molucas. Esta cuestión quedó solventada con la firma del Tratado de Zaragoza en 1529, por el que el emperador, acuciado por la necesidad de sufragar las campañas bélicas en curso, concertaba la venta de este territorio al rey luso por 350.000 ducados ${ }^{77}$.

75 ULLOA, 1977: 110. Véase también ROBLES SIERRA, 1990: 227-258.

76 La enemistad entre el Gran Canciller y el confesor real era notoria. Don Francesillo de Zúñiga hizo una maligna alusión en su Crónica («porque se quieren mucho», CRÓNICA DE DON FRANCESILLO DE ZÚÑIGA, 1855: 49b). Por su parte, Juan Dantiscus, el embajador polaco y amigo del Canciller, se quejaba del confesor imperial en una carta dirigida a Alonso de Valdés, fechada en Valladolid el $1^{\circ}$ de febrero de 1529. Allí denunciaba que fray García había tenido una amante, una cierta María de la Torre, que pasaba por santa, con quien había tenido dos hijos. Dantiscus deja entender que tenía razones análogas para interesarse por una pariente suya que había desposado con gran pompa en Burgos. Véase, CABALLERO, 1875: 409.

77 RODRÍGUEZ VILLA: 431. 


\section{CONSIDERACIONES FINALES}

García de Loaysa fue obispo de Osma, pero como tantos otros eclesiásticos cortesanos no residió en su diócesis ${ }^{78}$. De hecho, logró en 1526 un acuerdo «para que los interesados en los diezmos y otras rentas del Obispo y Cabildo de esta santa Iglesia, se conformasen con las particiones hechas por los Arciprestes, y que no violentasen a terceros $\gg{ }^{79}$. Asimismo, obtuvo en 1530 , cuando fue nombrado cardenal de Santa Susana por Clemente VII, las vacantes de los beneficios curados y no curados de su diócesis.

El oficio de confesor y su nombramiento como presidente del Consejo de Indias le obligaron a ocuparse de asuntos de Estado y esas ocupaciones, a su vez, lo convirtieron en un verdadero patrono cortesano. De allí que haya podido desarrollar una política clientelar que benefició a un buen número de familiares y amigos. Entre ellos, a Diego Beltrán, consejero de Indias, para quien en octubre de 1526 consiguió la merced del estanco de la recogida de pastel y orchilla, así como de la pesca del coral en todas la Indias. Al año siguiente, Beltrán obtuvo, junto al secretario Francisco de los Cobos, el derecho de establecer una compañía para el traslado de esclavos negros a las Indias para trabajar en las minas de Guatemala, concesión que estaba ligada al nombramiento de Alvarado como gobernador de esa región. Igualmente, en abril de 1528, le fueron concedidos los derechos de registro de las Audiencias de Santo Domingo y México. El incremento de sus ingresos económicos propició que Diego Beltrán encargase al arquitecto Luis de Vega la traza y obras del palacio de las Dueñas en Medina del Campo, tratando de imitar, en diversos aspectos, la casa que Cobos había mandado edificar en Valladolid ${ }^{80}$.

Álvaro de Loaysa y Toro obtuvo en 1527, con la ayuda del comendador de León, Francisco de los Cobos, un hábito de caballero de la Orden de Santiago. Éste no se había privado de mencionar en su relación de méritos los servicios prestados al emperador por su tío, el obispo de Osma ${ }^{81}$. Más adelante, el confesor real procedió a fundar mayorazgo a favor de Álvaro. Si su línea sucesoria no prosperaba, el beneficiario sería su sobrino nieto Diego Girón ${ }^{82}$.

78 Si bien el emperador había dispuesto en julio de 1524 que todos los obispos que quisiesen percibir sus beneficios debían residir en sus diócesis, habían sido exceptuados de la medida tres prelados: el arzobispo de Sevilla, el Presidente del Consejo de Castilla y el confesor real. RODRÍGUEZ VILLA: 201.

79 LOPERRAEZ CORVALÁN, 1788: 406.

80 PIZARRO LLORENTE, 2000: 62-66.

81 Genealogía de Alvaro de Loaysa y Toro, natural de Talavera, presentada para su ingreso en la Orden de Santiago en 1527. RAH, Salazar y Castro, 9/325, fo 37; Archivo Histórico Nacional, Consejo de Órdenes, Caballeros de Santiago, Exp.4513

82 BILLI DI SANDORNO, 1952: 103 - 104. 
Otro pariente favorecido fue Pedro Girón de Loaysa, quien actuó como corregidor de Vizcaya hasta 1528 y, por mediación de su tío, como oidor de la Chancillería de Valladolid a partir de entonces ${ }^{83}$. Asimismo, Loaysa patrocinó la carrera de Juan Suárez de Carvajal, casado con su sobrina Ana Girón, quien tras ser corregidor de Talavera y juez mayor de las tierras del Condestable, pasó en 1526 a ocupar una plaza de oidor en la Chancillería de Granada y en 1529 promocionó a la Chancillería de Valladolid. De allí pasó a ocupar una plaza como consejero de Indias, dejada tras la muerte de otro sobrino de Loaysa, Álvaro Núñez de Loaysa ${ }^{84}$.

Por último, fray García de Loaysa no dejó de favorecer a su Orden religiosa, no sólo enviando misioneros a las Indias, sino también encargándose de la reforma de los conventos de la Corona de Aragón, al enviar desde el Convento de San Esteban, como su vicario, a fray Domingo de Montemayor ${ }^{85}$. A ello agregó la construcción y embellecimiento de algunos conventos, entre los que destaca el de San Ginés de Talavera, su ciudad natal, donde ordenó posteriormente el traslado de los restos de sus padres, así como la construcción para ellos y para sí mismo de unos monumentales sepulcros del más puro estilo renacentista ${ }^{86}$.

\section{BibLIOGRAFÍA}

Acta Capitulorum Generalium Ordinis Praedicatorum, Benedictus Maria Reichert (ed.), vol. IV, Roma, Ex Typographia Polyglota, 1901.

Beltrán de Heredia, Vicente, Cartulario de la Universidad de Salamanca, II, Salamanca, Universidad de Salamanca, 1970.

Beltrán de Heredia, Vicente, Historia de la reforma de la Provincia dominicana de España, Roma, Istituto Storico Dominicano, 1939.

Benítez Sánchez-Blanco, Rafael, «La política de Carlos V hacia los moriscos granadinos», en José Martínez Millán (coord.), Carlos V y la quiebra del humanismo político en Europa (1530-1558), 1, Madrid, Sociedad Estatal para la Acción Cultural Exterior, 2001; 415-446.

83 CARLOS MORALES, 2000: 177.

84 PIZARRO LLORENTE, 2000: 402-407.

85 «En el caso concreto de Aragón vieron como de 56 conventos existentes (de los que 14 eran femeninos) antes de 1500 se incrementaban en 20 (de los que 14 eran masculinos) a lo largo de la primera mitad del siglo XVI. En 1530, un breve autorizaba al provincial dominico de España a enviar a Aragón a algunos religiosos para que recorrieran los conventos y, con los que se les unieran, formaran una congregación de observancia que dependería del provincial de Castilla, algo que los aragoneses no podían admitir». MARTÍNEZ RUÍZ, 2004: 135.

86 NICOLAU CASTRO, 2003: 267 a 276. 
Billi di Sandorno, Amalia, «Documentos inéditos e interesantes de la vida del Cardenal Loaysa», Hispania Sacra, 5 (1952), 103-104.

Brandi, Karl, Carlos V, Madrid, Editora Nacional, 1949.

Caballero, Fermín, Conquenses ilustres. Tomo IV, Alonso y Juan de Valdés, Madrid, Oficina Tipográfica de Oficio, 1875.

Cadenas y Vincent, Vicente de, Diario del emperador Carlos V: itinerarios, permanencias, despacho, sucesos y efemérides relevantes de su vida, Madrid, Hidalguía, 1992

Carlos Morales, Carlos Javier de, "Girón de Loaysa, Pedro», en José Martínez Millán, La corte de Carlos V. Vol. 3, Los consejeros y los consejos, Madrid, Sociedad Estatal para la conmemoración de los centenarios de Felipe II y Carlos V, 2000: 177.

Carlos Morales, Carlos Javier de, «La participación en el gobierno a través de la conciencia regia: fray Diego de Chaves, o.p., confesor de Felipe II», en Flavio Rurale, I religiosi a Corte. Teología, política e diplomazia in Antico Regime, Roma, Bulzoni, 1998; 131-157.

Carreras López, Juan José, «The Court Chapel: a Musical Profile and the Historiographical Context of an Institution», en Juan José Carreras López, Bernardo José García García, Tess Knighton (ed.), The Royal Chapel in the Time of the Habsburgs: Music and Court Ceremony in the Early Modern Europe, Woodbridge, The Boydell Press, 2005; 8-22.

Cartas del famoso conquistador Hernán Cortés al emperador Carlos Quinto, México, Imprenta de I. Escalante, 1870.

Cauchies, Jean-Marie, "¡¡No tienen más voluntad de yr a España que de yr al Infierno!' Los consejeros 'flamencos' de Felipe el Hermoso y del joven Carlos V frente a la herencia española», en Antonio Álvarez-Osorio Alvariño y Bernardo García García, La Monarquía de las Naciones. Patria, nación y naturaleza en la Monarquía de España, Madrid, Fundación Carlos de Amberes, 2004; 121-130.

Cedulario Indiano, libro II, Madrid, Ediciones Cultura Hispanica, 1945.

Chipman, Donald, Nuño de Guzmán y la Provincia de Pánuco en la Nueva España, Madrid, CSIC, 2007.

Colección de documentos inéditos relativos al descubrimiento, conquista y organización de las antiguas posesiones españolas de ultramar, Serie 2, vol. 14, Madrid, Real Academia de la Historia, 1923.

Collection des Voyages des Souverains des Pays-Bas, T. XII, Itinéraire de CharlesQuint de 1506 a 1551. Journal des voyages de Charles-Quint, de 1514 a 1554, par Jean de Vandenesse, Louis Prosper Gachard (ed.), Bruselas, F. Hayez, 1874.

Crónica de don Francesillo de Zúñiga, edición de Pascual Gayangos, Madrid, BAE, 1855 [1529].

Cruz, Juan de la, Coronica de la Orden de Predicadores, de su principio y suceso hasta nuestra edad, I, Lisboa, Imprenta de Manuel Juan, 1567.

Disposiciones complementarias de las Leyes de Indias, Madrid, 1930.

Dolores Sánchez, El deber de consejo en el estado moderno: las juntas «ad hoc» en España (1474-1665), Madrid, Polifemo, 1993. 
Fagel, Raymond, «Carlos de Luxemburgo. El futuro Emperador como joven príncipe de Borgoña (1500-1516)», en Pedro Navascués Palacios (ed.), Carolus V Imperator, Barcelona, Lunwerg, 1999; 29-63.

Fernández Conti, Santiago, «Jean Glapion», en José Martínez Millán, La corte de Carlos V. Vol. 3, Los consejeros y los consejos, Madrid, Sociedad para la conmemoración de los centenarios de Carlos V y Felipe II, 2000; 177-178.

Fernández Rodríguez, Pedro, Los dominicos en el contexto de la primera, evangelización de México, 1526-1550, Salamanca Ed. San Esteban, 1994.

Gómez-Menor Fuentes, Juan Carlos, «Los Loaysas de Talavera de la Reina, señores de Huerta de Valdecarábanos», Anales Toledanos, 26 (1989), 353-380.

González Dávila, Gil, Teatro Eclesiástico de las ciudades e iglesias catedrales de España, 4, Salamanca, Imprenta de Antonia Ramírez, 1618.

Goñi Gaztambide, José, «Fray Juan de Monzón, O. P., su vida y sus obras (c. 1340-c. 1412)», Boletin de la Sociedad Castellonense de Cultura Castellon de la Plana, 66/3-4, 1980; 506-523.

Goñi Gaztambide, José, «La polémica sobre el bautismo de los moriscos a principios del siglo XVI», Anuario de Historia de la Iglesia, 16 (2007), 209-216.

Hernández, Ramón «Actas del capítulo provincial de Salamanca de 1522», Archivo Dominicano, XIX (1998), 6-25.

Hernández, Ramón, «Texto de las ordenaciones de García de Loaysa», Archivo Dominicano, XVII, 1996; 5-13.

Keniston, Hayward, Francisco de los Cobos. Secretario de Carlos V, Madrid, Castalia, 1980.

La Selle, Xavier de, Le service des âmes à la Cour. Confesseurs et aumôniers des rois de France du XIIIème au Xèeme siècle, Paris, École de Chartres, 1995.

Lippens, Hugolinus, «Jean Glapion défenseur de la Réforme de l'Observance», Archivum Franciscanum Historicum 44 (1951), 3-70.

Longo, Carlo, «Hurtado de Mendoza (Juan)», Roger Aubert (dir.), Dictionnaire d'Histoire et de Geographie Ecclésiastiques, t. VIII, Paris, Letouzey et Ané, 1995, col. 427-430.

Loperraez Corvalán, Juan, Descripción histórica del Obispado de Osma, Tomo Primero, Madrid, Imprenta Real, 1788.

López Arandia, María Amparo, «El confesionario regio en la monarquía hispánica del siglo XVII», Obradoiro de Historia Moderna, 19 (2010), 249-278.

López de Gomara, Francisco, Historia de México, con el descubrimiento de la Nueva España, conquistada por el muy illustre y valeroso Príncipe don Fernando Cortes, Marqués del Valle, Amberes, Casa de Juan Steelsio, 1554.

López de Haro, Alonso, Nobiliario genealógico de los reyes y títulos de España, Madrid, Imprenta de la viuda de Fernando Correa de Montenegro, 1622.

Martín Tamayo, Fausto, Nuño de Guzmán, México, Siglo XXI, 1992.

Martínez Millán, José, «Corrientes espirituales y facciones políticas en el servicio del emperador Carlos V», en Wim Blockmans y Nicolette Mount, The World of Emperour Charles V, Amsterdam, Royal Netherlands Academy, 2004; 97-126. 
Martínez Millán, José, «En busca del equilibrio en la corte de Carlos V (1522-1529)», La corte de Carlos V, Vol. 1, Corte y gobierno, Madrid, Sociedad Estatal para la Conmemoración de los Centenarios de Felipe II y Carlos V, 2000; 207-159.

Martínez Millán, José, Rivero Rodríguez, Manuel, «La coronación imperial de Bolonia y el final de la 'vía flamenca' (1526-1530)», en José Martínez Millán (coord.), Carlos V y la quiebra del humanismo político en Europa (1530-1558), Vol. 1, Madrid, Sociedad Estatal para la Conmemoración de los Centenarios de Felipe II y Carlos V, 2001; 131-150.

Martínez Ruíz, Enrique, El peso de la Iglesia, Madrid, Actas, 2004.

Meester, Patrice de, «Francisco de Quiñones de León, envoyé de Clément VII auprès de Charles Quint, et son tombeau», Miscellanea Neerlandica, XXV (2001), 197-213.

Mendoza y Bobadilla, Francisco de, El tizón de la nobleza de España, versión pal. de Armando Escobar Olmedo, México, F.A.H., 1999 [1560].

Minguella y Arnedo, Toribio, Historia de la diócesis de Sigüenza y de sus obispos, Madrid, Imp. de la Revista de Arch., Bibl. y Museos, 1912.

Mora, Esteban, Historia analística del Convento de San Esteban de Salamanca, II, Salamanca, 1730 [inédito].

Mortier, Antonin, Histoire des Maitres Généraux de l'Ordre de Freres Prêcheur, T. V, Paris, Alphonse Picard, 1911.

Nicolau Castro, Juan, «Los sepulcros del cardenal fray García de Loaysa y sus padres en el monasterio dominico de Talavera de la Reina», Archivo Español de Arte, LXXVI (2003), 267-276

Nieto Soria, José Manuel, Iglesia y génesis del Estado Moderno en Castilla (13691480), Madrid, Editorial Complutense, 1995.

Nieva Ocampo, Guillermo, «La observancia dominica y la monarquía castellana: compromiso político y disciplinamiento social (1460-1550)», en José Martínez Millán (coord.), La corte en Europa: política y religión (siglos XVI-XVIII), Vol. I, Madrid, Polifemo, 2012; 513-561.

Nieva Ocampo, Guillermo, «Monarquía y clero regular: Los dominicos de Castilla durante el reinado de Enrique III y la minoría de Juan II», Cuadernos de Historia de España, 85-86 (2012), 525-541.

Nogales Rincón, David, «Confesar al rey en la Castilla bajomedieval (1230-1504)», en Carrasco Manchado, Ana Isabel y Rábade Obradó, María del Pilar (coord.), Pecar en la Edad Media, Madrid, Sílex, 2008; 55-80.

Nogales Rincón, David, La representación religiosa de la Monarquía castellanoleonesa: la capilla real (1252-1504), Madrid, 2009, Tesis doctoral inédita.

Olmeda, Sebastián, Chronica Ordinis Praedicatorum [1546], Manuel Canal Gómez editor, Roma, Institutum Historicum Fratrum Praedicatorum, 1936.

Pacheco Jiménez, César, «El regimiento de Talavera de la Reina en el siglo XV», Cuaderna. Revista de estudios humanísticos de Talavera y su antigua tierra, 6 (1998), 44-53.

Pedro Fernández Rodríguez, Los dominicos en la primera evangelización de México, Salamanca, ed. San Esteban, 1994. 
Pérez, Joseph, La revolución de las Comunidades de Castilla (1520-1521), Madrid, 2005 [ $1^{\circ}$ ed. 1976].

Pizarro Llorente, Henar, «Beltrán, Diego», en J. Martínez Millán, La corte de Carlos V. Vol. 3, Los consejeros y los consejos, Madrid, 2000; 62-66.

Pizarro Llorente, Henar, «El control de la conciencia regia. El confesor real Fray Bernardo de Fresneda», José Martínez Millán (dir.), La corte de Felipe II, Madrid, Alianza, 1994; 149-188.

Pizarro Llorente, Henar, «Suárez de Carvajal, Juan», en J. Martínez Millán, La corte de Carlos V. Vol. 3, Los consejeros y los consejos, Madrid, 2000; 402-407.

Poutrin, Isabelle, «Los confesores de los Reyes de España: carrera y función (s. XVIXVII)», en Cortes Peña, Antonio Luis, Betrán, José Luis y Serrano Martín, Eliseo (ed.), Religión y poder en la Edad Moderna, Granada, Editorial Universidad de Granada, 2005; 67-81.

Relazioni degli ambasciatori veneti al Senato, racolte, annotate ed edite da Eugenio Albèri, Firenze, Serie $I^{a}$-Volume $I I^{\circ}$, Florencia, Tipografia e calcografia all'insegna di Clio, 1840.

Remesal, Antonio de, Historia de la Provincia de San Vicente de Chiapas y Guatemala, Madrid, Imprenta de Francisco Abarca de Angulo, 1619.

Rivero Rodríguez, Manuel, Gattinara. Carlos $V$ y el sueño del Imperio, Madrid, Sílex, 2005.

Rivero Rodríguez, Manuel, La edad de oro de los virreyes. El virreinato en la Monarquía hispana durante los siglos XVI y XVII, Madrid, Alianza, 2011.

Robles Sierra, Adolfo, «Una aproximación a Domingo de Betanzos. A propósito de su carta de 1540», en Los dominicos y el Nuevo Mundo: Actas del II Congreso Internacional. Salamanca, 28 de marzo-1 de abril de 1989, Salamanca, San Esteban, 1990; 227-258.

Rodríguez Villa, Antonio, El emperador Carlos $V$ y su corte según las cartas de don Martín de Salinas, embajador del infante don Fernando (1522-1539), Madrid, Establecimiento tipográfico de Fortanet, 1903.

Röhrkasten, Jens, The Mendicant Houses of Medieval London, 1221-1539, Muster, Lit Verlag, 2004.

Sandoval, Prudencio de, Historia del emperador Carlos V, rey de España, $t$. III., Madrid, 1846 [1604-1606].

Santa Cruz, Alonso de Crónica del emperador Carlos V, T. 2, Madrid, Real Academia de la Historia, 1920 [1551].

Ulloa, Daniel, Los predicadores divididos. Los Dominicos en la Nueva España en el siglo XVI, México, El Colegio de México, 1977.

Recibido: 09/09/2013

Aceptado: 14/04/2014 